\title{
Optimasi Presensi Praktikan Berbasis GPS dengan Fuzzy Logic dan K-Mean
}

\author{
Mohammad Harry Khomas Saputra ${ }^{\mathrm{a} 1}$, Muhammad Yusril Helmi Setyawan ${ }^{\mathrm{a} 2}$ \\ ${ }^{a}$ Teknik Informatika, Politeknik Pos Indonesia \\ Jl. Sariasih 54 Sarijadi, Bandung \\ ${ }^{1}$ harrysaputraepoltekpos.ac.id \\ 2yusrilhelmilpoltekpos.ac.id
}

\begin{abstract}
Abstrak
Praktikum dalam proses pembelajaran merupakan hal yang tak terpisahkan dalam upaya membentuk karakter dan kompetensi mahasiswa untuk menghadapi dunia kerja. Diperlukan upaya-upaya khusus agar tujuan utamanya tercapai. Salah satunya adalah menyediakan sistem presensi yang mampu memonitoring kinerja mereka (praktikan) secara real time dan efisien. Paper ini memaparkan sebuah usulan tentang penerapan metode fuzzy logic dan K-Means pada aplikasi presensi berbasis GPS untuk mengoptimasi keputusan terkait kinerja praktikan dan statusnya dalam presensi.
\end{abstract}

Kata kunci: Presensi, GPS, Praktikan, Fuzzy Logic, K-Means

\section{Optimization of GPS Based Student Attendance with Fuzzy Logic and K-Mean}

\begin{abstract}
Practicum in the learning process is inseparable to shape student character and competence to face the world of work. It takes special efforts to achieve its main goal. One of them is to provide a presence system that can monitor their performance (practitioners) in real-time and efficiently. This paper presents a proposal on the application of fuzzy logic and K-Means methods in GPS-based presence applications to optimize decisions regarding the performance of the practitioner and its status in presence.
\end{abstract}

Keywords: Attendance, GPS, Students, Fuzzy Logic, K-Means

\section{PEndahuluan}

Istilah praktikan menurut Kamus Besar Bahasa Indonesia (KBBI) adalah seseorang yang mengikuti praktikum. Adapaun praktikum yang dimaksud adalah pelaksaaan kegiatan Praktek Kerja Lapangan (PKL) atau magang industri yang dalam aturannya dilaksanakan diluar kampus. Keterlibatan pihak ketiga dan pelaksanaan kegiatannya yang dilakukan di lokasi yang berbeda-beda untuk setiap mahasiswa, menjadikan proses administrasi kegiatan dan monitoringnya lebih rumit. Maka keterlibatan teknologi sungguh dibutuhkan untuk meningkatkan efisiensi kinerja [1] proses administrasi bagi penyelenggara kegiatan ini.

Banyak aplikasi telah dikembangkan oleh berbagai pihak, termasuk aplikasi presensi berbasis GPS (Global Positioning System). GPS merupakan bagian dari Global Navigation Satellite System (GNSS). GNSS adalah sistem untuk penentuan lokasi atau posisi -sehingga disebut sebagai penentuan posisi geografis. Teknologi ini bekerja dengan menggunakan penerima khusus, posisi geo dalam ruang dan waktu dapat dihitung berdasarkan penerimaan sinyal satelit [6][10][14]. Para pengembang dengan berbagai karakteristik aplikasinya tentu merupakan pilihan yang dilakukan untuk menyesuaikan dengan kebutuhan dan karakteristik penggunanya.

Selaras dengan hal tersebut, peneliti merasa perlu untuk berkontribusi dalam upaya meningkatkan kemampuan dari aplikasi sejenis, yaitu dengan memfokuskan pada kemampuan mengoptimasi kinerja sistem. Yaitu bertujuan menghasilkan keputusan yang realible dalam menentukan status praktikan pada proses presensi praktikan di lapangan (lokasi magang).

Dilain sisi, isu ketepatan posisi juga menjadi hal yang menjadi keniscayaan pada aplikasi-aplikasi berbasis GPS [2]. Ketepatan lokasi antara area tempat magang dengan posisi praktikan melakukan presensi menjadi sangat penting, sistem akan terus mencatat perubahan lokasi posisi (longitude dan latitude) pada GPS ponsel praktikan, hal tersebut menjadi persoalan ketika praktikan berubah posisi dari titik koordinat sebelumnya. Oleh sebab itu optimasi dilakukan terhadap keakuratan pada posisi tempat magang dengan menambahkan area sehingga ketika pergerakan praktikan masih dalam area lokasi tempat magang maka praktikan masih dinyatakan hadir 
dan diukur kinerjanya berdasarkan waktu atas keberadaan praktikan di area tempat magang dilakukan.

Untuk dapat melakukan proses penentuan ketepatan posisi dengan area maka peneliti menggunakan fuzzy logic (Logika Fuzzy) yang akan mengolah data setiap pergerakan praktikan dan menentukan kinerja berdasarkan waktu dan posisi pada area magang, sedangkan k-means di terapkan untuk mengelompokan data lokasi dan waktu sehingga dapat ditentukan praktikan tersebut masih berada pada area tempat magang atau tidak, sebagai salah satu indikator kepatuhan. Praktikan dinyatakan memiliki kepatuhan atau kinerja baik ketika berada didalam area yang telah ditentukan dengan rentang waktu tertentu.

Penelitian ini diharapkan mampu menjadi bagian dari solusi dari permasalahan yang umum dihadapi penyelenggara kegiatan PKL terkait dengan proses monitoring produktivitas dan evaluasi kehadiran praktikan di lokasi kegiatan serta untuk memastikan capaian pembelajaran setiap harinya.

\section{MetodoloGi}

Metodologi penelitian mengacu pada langkah-langkah berikut:

1. Memilih sampling data praktikan yang diperoleh dari lokasi yang berbeda-beda

2. Pengambilan data lokasi praktikan berupa longitude dan latitude sebagai lokasi acuan

3. Penghitungan radius sebagai perbandingan antara koordinat lokasi acuan dengan koordinat lokasi device praktikan menggunakan perhitungan Harversine

4. Perhitungan fuzzy logic untuk menentukan status presensi mahasiswa

5. Perhitungan K-Means untuk melakukan perengkingan terhadap tingkat kepatuhan sebagai representasi dari kinerja praktikan

\section{HASIL DAN PEMBAHASAN}

\section{A. Pemilihan Sampling \& pengambilan data lokas}

Penelitian yang dilakukan terhadap 67 praktikan dilokasi magang yang berbeda-beda. Selama 1 (satu) bulan, praktikan di pantau posisi pergerakan selama melaksanakan magang di lokasi praktek masing masing, pengambilan data posisi setiap harinya diambil sebanyak 4 (empat) kali, adapun waktu pengambilan data posisi yaitu jam 9:00, 11:00, 13.00, dan 16:00. Berikut ini adalah gambaran posisi koordinat lokasi mahasiswa setiap hari.

Gambar 1 menunjukan sebaran posisi device mahasiswa setiap harinya yang digambarkan dengan marker kecil sedangkan marker yang berukuran besar merupakan marker acuan yang digunakan sebagai pembanding untuk menentukan jarak. Secara detail data lokasi tersebut diuraikan dalam Tabel I.

Tabel I menunjukan data latitud dan longitude dari yang diambil berdasarkan posisi device, dimana data ini akan dikonversi menjadi data jarak menggunakan peritungan Harversine.

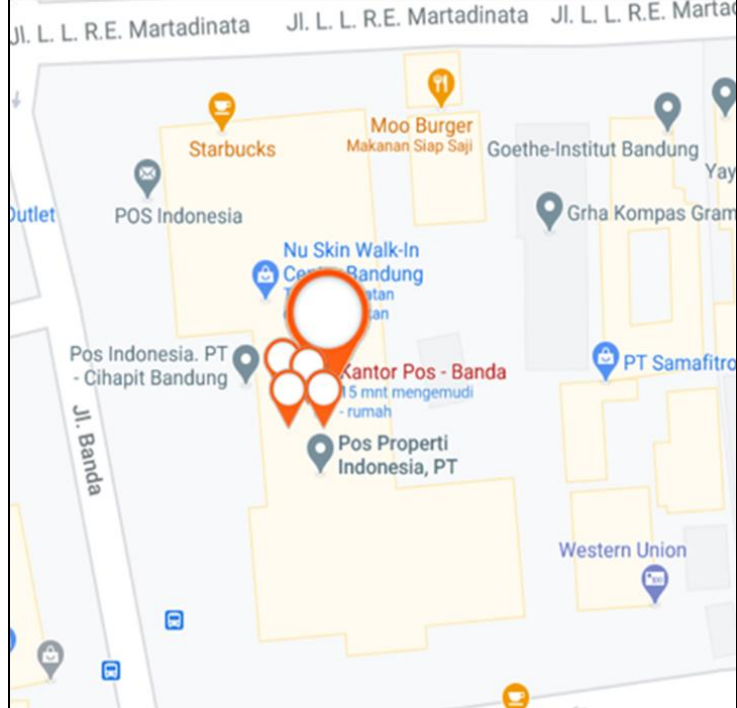

Gambar 1. Sebaran posisi lokasi praktikan

TABEL I

KOORDINAT LOKASI

\begin{tabular}{|l|l|}
\hline Latitude & Longitude \\
\hline-6.906 .788 & 107.617 .294 \\
\hline-6.906 .744 & 107.617 .361 \\
\hline-6.906 .860 & 107.617 .397 \\
\hline-6.906 .816 & 107.617 .310 \\
\hline
\end{tabular}

\section{B. Perhitungan Radius}

Data yang diperoleh pada Table 1 melalui Haversine Formula selanjutnya akan dihitung jarak antara dua titik, berdasarkan posisi garis lintang latitude dan posisi garis bujur longitude sebagai variabel inputan.

Haversine Formula

$$
\begin{aligned}
& x=(\operatorname{lng} 2-\operatorname{lng} 1) * \cos \left(\frac{\operatorname{lat} 1+\operatorname{lat} 2}{2}\right) ; \\
& y=(\operatorname{lat} 2-\operatorname{lat} 1) ; \\
& d=\operatorname{sqrt}(x * x+y * y) * R
\end{aligned}
$$

Keterangan :

$$
\begin{aligned}
& x=\text { longitude }(\text { lintang }) \\
& y=\text { latitude }(\text { bujur }) \\
& d=\text { jarak }(\mathrm{km}) \\
& R=\text { Radius } \text { Bumi }=6371 \mathrm{~km} \\
& 1 \text { derajat }=0.0174532925 \text { radian }
\end{aligned}
$$

Dari tabel jarak didapatkan 4 (empat) data jarak setiap harinya. Data tersebut kemudian dilakukan perhitungan menggunakan algoritma fuzzy untuk menentukan apakah mahasiswa tersebut disimpulkan masuk atau tidak setiap harinya. Himpunan fuzzy untuk jarak sebagai jarak pada penelitian ini adalah dekat $[0,50]$, sedang $[50,150]$ dan jauh $[150, \sim]$ 


\section{Perhitungan Fuzzy}

Variabel yang dipilih untuk perhitungan fuzzy pada kasus ini yaitu jarak; dekat sedang dan jauh yang digambarkan keanggotaannya yang dapat dilihat pada Gambar 2.

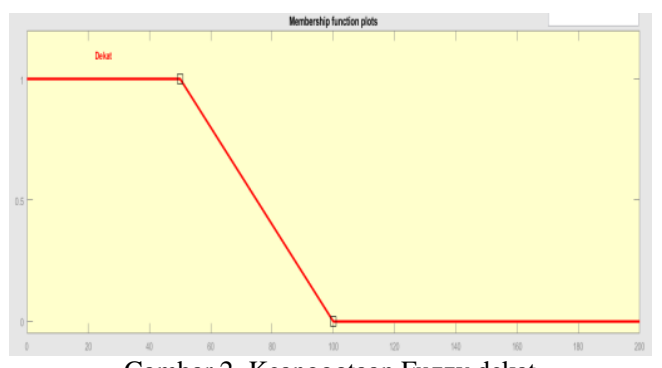

Gambar 2. Keanggotaan Fuzzy dekat

Gambar 2 menunjukan keanggotaan fuzzy dekat yang digambarkan dengan trapesium, dengan persamaan sebagai berikut

$$
\mu[x]= \begin{cases}0 ; & x \leq a \text { atau } \mathrm{x} \geq \mathrm{d} \\ (\mathrm{x}-\mathrm{a}) /(\mathrm{b}-\mathrm{a}) ; & \mathrm{a} \leq \mathrm{x} \leq \mathrm{b} \\ 1 ; & \mathrm{b} \leq \mathrm{x} \leq \mathrm{c}\end{cases}
$$

Dimana $c=50$ dan $d=100$

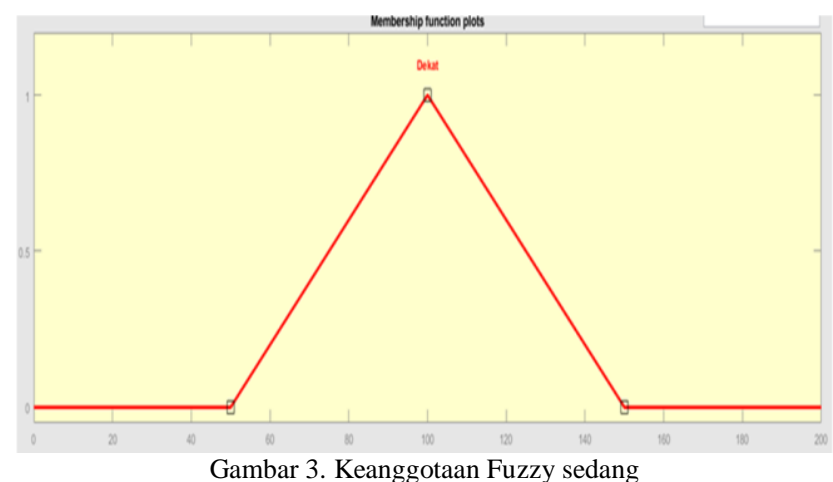

$$
\mu[x]= \begin{cases}0 ; \\ (\mathrm{x}-\mathrm{a}) /(\mathrm{b}-\mathrm{a}) ; & \mathrm{a} \leq \mathrm{x} \leq \mathrm{b} \\ (\mathrm{b}-\mathrm{x}) /(\mathrm{c}-\mathrm{b}) ; & \mathrm{b} \leq \mathrm{x} \leq \mathrm{c}\end{cases}
$$

Dimana $a=50, b=100$, dan $c=150$

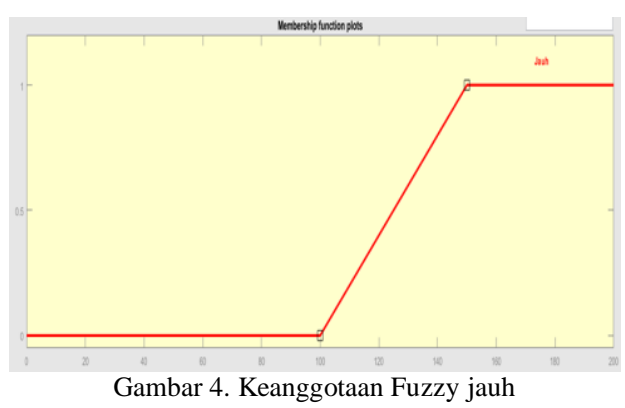

$$
\mu[x]= \begin{cases}0 ; & x \leq a \text { atau } \mathrm{x} \geq \mathrm{d} \\ (\mathrm{x}-\mathrm{a}) /(\mathrm{b}-\mathrm{a}) ; & \mathrm{a} \leq \mathrm{x} \leq \mathrm{b} \\ 1 ; & \mathrm{b} \leq \mathrm{x} \leq \mathrm{c} \\ (\mathrm{d}-\mathrm{x}) /(\mathrm{d}-\mathrm{c}) ; & x \geq d\end{cases}
$$

Dimana $a=100$, dan $b=150$.

Selanjutnya himpunan fuzzy untuk Jarak, sebagai variabel input yang berlaku untuk input Jarak1, Jarak2, Jarak2, dan Jarak4 dapat dilihat pada Gambar 5.

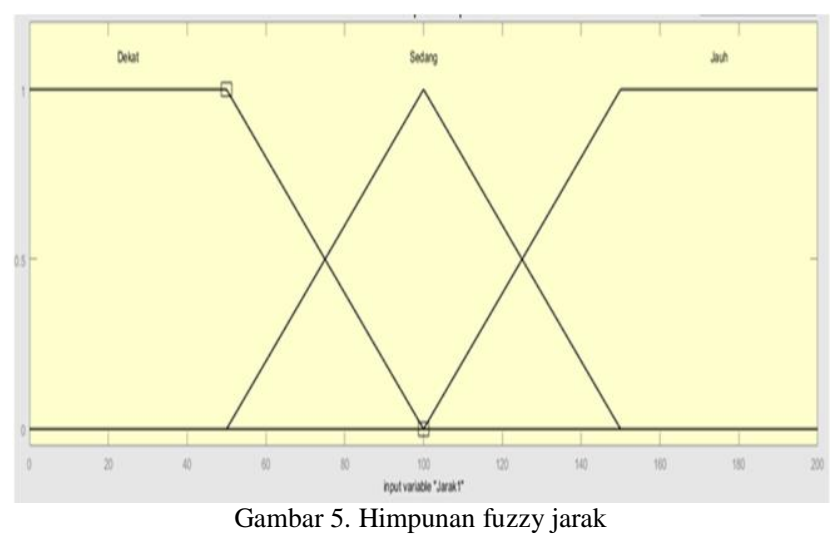

Dalam proses fuzikasi (lihat Gambar 6), proses pengambilan data akan dilakukan 4 kali sebagai input

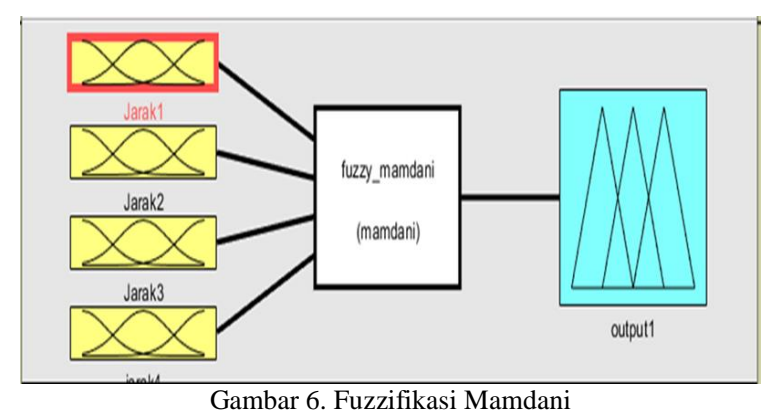

Dan terdapat 14 rule yang diorientasikan untuk menagani setiap inputan sehingga dapat menentukan status presensi kehadiran praktikan.

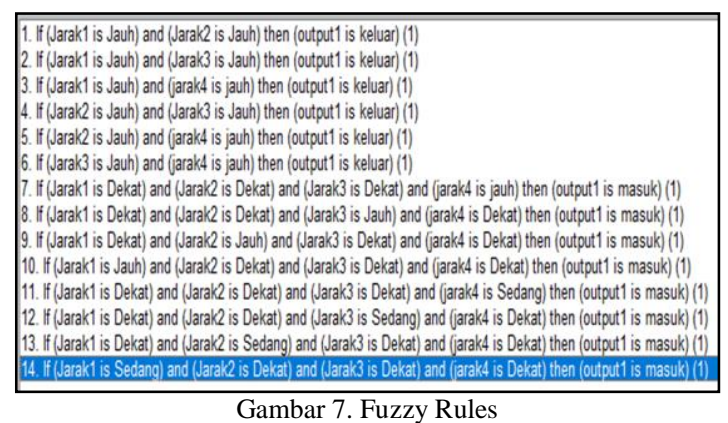

\section{Eksperimen}

Kasus 1 : Simulasi perhitungan dilakukan dengan inputan jarak $1=8$, jarak $2=6$, jarak $3=9$, jarak $4=10$ dan menghasilkan inferensi fuzzy yang dapat dilihat pada Gambar 8. 


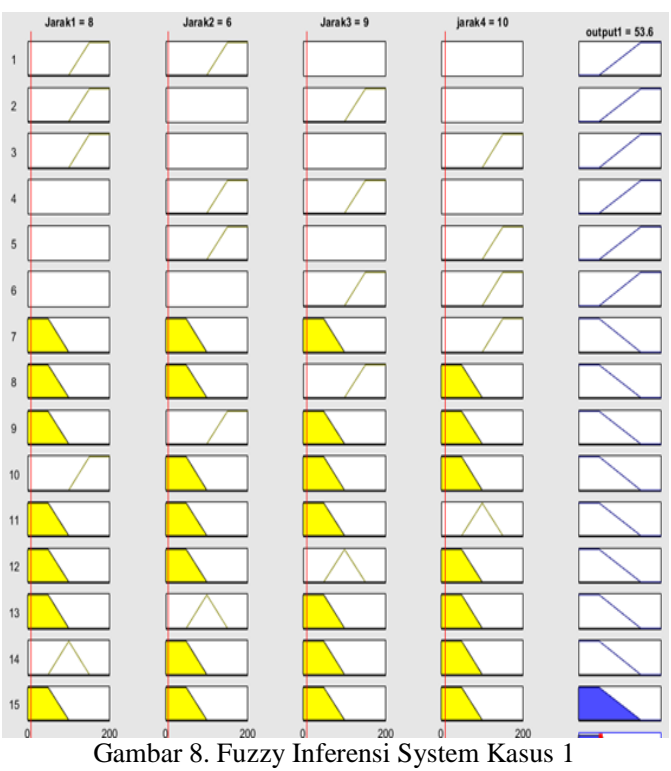

Kasus 2 : dilakukan input terhadap jarak $1=30$, jarak 2 $=50$, jarak $3=150$, jarak $4=160$

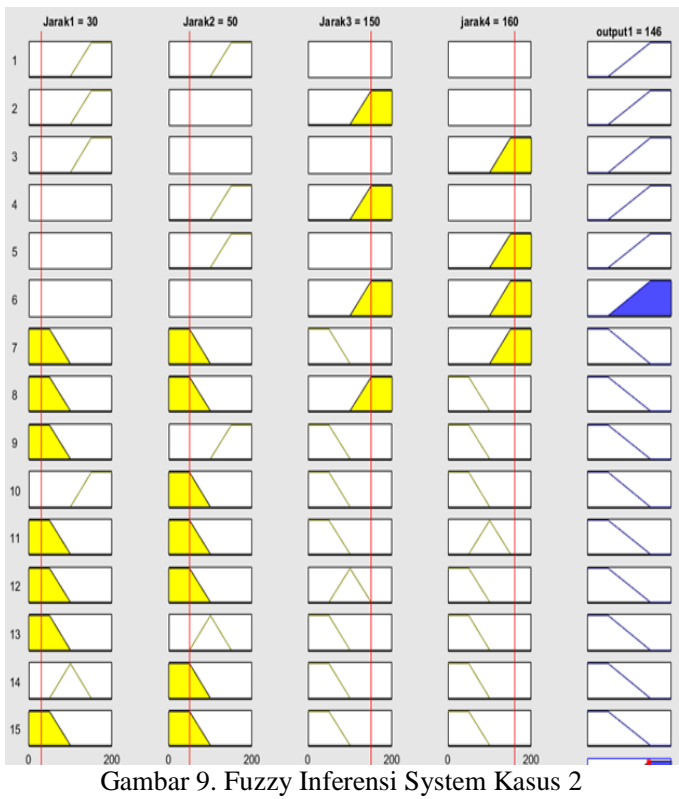

\section{E. Hasil Eksperimen Fuzzy}

Mengacu pada gambar 8, maka dihasilkan praktikan dinyatakan berstatus hadir dengan derajat 53.6. Sedangkan untuk kasus 2 yang mengacu digambar 9, maka kesimpulannya mahasiswa dinyatakan tidak hadir, karena dari 4 kali pengambilan data terdapat 2 data jarak yang termasuk kedalam kategori jauh dengan derajatnya yaitu 146

\section{F. Perhitungan K-Means}

Mengacu pada parameter jarak yang digunakan untuk menentukan status kehadiran diatas maka peneliti melanjutkannya untuk menentukan kelompok kepatuhan praktikan dalam melaksanakan kegiatan. Praktikan dikelompokan menggunakan metode K-Mean dengan 2 parameter yaitu total akumulasi jarak dan banyaknya kemunculan jarak dengan kategori jauh yaitu lebih dari
150 meter. Dari hasil perhitungan setelah iterasi ke-6 menggunakan K-Mean, maka dari 67 sample data terdapat 3 kelompok yaitu 28 orang dengan kepatuhan baik, 35 orang dengan kepatuhan sedang dan 4 orang dengan kepatuhan buruk.

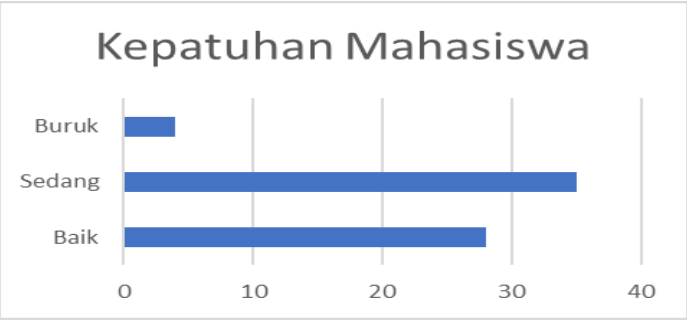

Gambar 10. Cluster kepatuhan mahasiswa

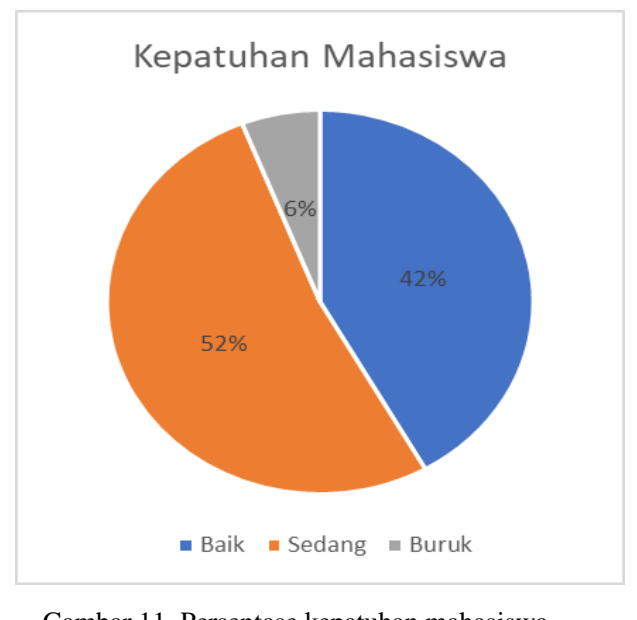

Gambar 11. Persentase kepatuhan mahasiswa

Berdasarkan Gambar 11, kepatuhan mahasiswa berdasarkan posisi dan jarak pada saat internsip yang memiliki kepatuhan baik sebesar $42 \%$ dan yang memiliki kepatuhan sedang cukup mendominasi yaitu sebesar 52\%, sedangkan yang memiliki kepatuhan buruk hanya $6 \%$. Dengan demikian algoritma fuzzy dengan metode mamdani dapat digunakan untuk menentukan kehadiran mahasiswa di tempat magang dengan menggunakan perhitungan jarak, dan K-mean dapat digunakan untuk mengelompokan kepatuhan mahasiswa.

\section{KESIMPULAN}

Luaran data hasil kinerja GPS sebagai basis informasi untuk pengelolaan sistem monitoring kegiatan sangat relevan dengan prinsip efisiensi monitoring kegiatan jarak jauh, namun melalui perluasan pemanfaatan basis data yang terhimpun tersebut untuk menghasilkan informasi yang lain tentu dapat dimanfaatkan dalam rangka mengoptimasikan kemampuan sistem dalam proses monitoring. Penelitian ini telah menghasilkan proses otomatisasi dalam memutuskan status kehadiran mahasiswa melalui inputan data GPS praktikan menggunakan Fuzzy Logic dan menentukan kelompok kepatuhan dengan menggunakan K-Means.

\section{DAFTAR PUSTAKA}

[1] Kemendikbud, "PERATURAN MENTERI PENDIDIKAN DAN KEBUDAYAAN NO 3 TENTANG STANDAR NASIONAL PENDIDIKAN TINGGI," Kementrian Pendidikan dan Kebudayaan, Jakarta, 2020 
[2] S. Pooja, "Vehicle Tracking System Using GPS," International Journal of Science and Research (IJSR), 2013.

[4] T. Sutrisno, "Upaya Meningkatkan Kedisiplinan Mahasiswa Semester III Pendidikan Guru Sekolah Dasar Universitas Bangun Nusantara Sukoharjo Dalam Mengikuti Pembelajaran Mata Kuliah Kesamaptaan Melalui Reinforcement (Penguatan)," Jurnal Bidang Pendidikan Dasar (JBPD), 2017.

[5] K. I. S. A. P. K. B. Priti Jadhav, "Student Tracking System Using GSM and GPS Technology," International Journal of Innovative Research in Computer and Communication Engineering(IJIRCCE), 2017

[6] V. D. C. D. K. P. R. Hitesh S. Chaudhari, "Review on Personal Tracker Systems," International Journal of Engineering Research \& Technology (IJERT), 2017.

[7] C. J. H. Elliott D. Kaplan, Understanding GPS: Principles and Applications, Massachusetts: Bedford, 2005.

[8] S. Parkinson, The global positioning system. American Institute of Aeronautics and Astronautics, 1996.

[9] N. A. R. L. D. C. L. M. \&. C. A. Cheever, "The impact of restricting wireless mobile device use on anxiety levels among low, moderate and high users," Computers in Human Behavior, pp. 290-297, 2014

[10] A. K. Dubey, U. Gupta and S. Jain, "Comparative Study of K means and Fuzzy C-means Algorithms on The Breast Cancer Data," International Journal on Advanced Science Engineering Information Technologi, pp. 18-28, 2018

[11] P. B. Shruti Bansal, "Smoothing of GPS-based Timing Data by Moving Average Technique Utilizing Fuzzy Logic," in International Conference on Signal Processing and Integrated Networks (SPIN), India, 2014.

[12] S. Alagic, Object-Oriented Technology, Switzerland: Springer International Publishing, 2015.

[13] J. E. K. Kenneth E. Kendall, Systems Analysis and Design, Pearson, 2010

[14] S. B. H. K. A. D. Amol Chaudhari, "GPS/GSM Enabled Person Tracking System," International Journal of Innovative Research in Science, Engineering and Technology(IJIRSET), 2015.

[15] A. B. A. A. M. Loay F. Hussein, "Design of GPS System for Tracking a Life Vest," International Journal of Computer Science and Information Security (IJCSIS), 2019.

[16] H. S. K. S. Abha Damani, "Global Positioning System for Object Tracking," International Journal of Computer Applications, 2015.

[17] wikipedia, "GNSS_applications," 2019. [Online]. Available: http://en.wikipedia.org/wiki/GNSS_applications. 